\title{
Severe SARS-CoV-2 infection in a cat with hypertrophic cardiomyopathy
}

\section{Francisco R. Carvallo}

Department of Biomedical Sciences \& Pathobiology, Virginia-Maryland College of Veterinary Medicine, Virginia Tech

\section{Mathias Martins}

Department of Population Medicine and Diagnostic Sciences, Animal Health Diagnostic Center, College of Veterinary Medicine, Cornell University

\section{Lok R. Joshi}

Department of Population Medicine and Diagnostic Sciences, Animal Health Diagnostic Center, College of Veterinary Medicine, Cornell University

\section{Leonardo C. Caserta}

Department of Population Medicine and Diagnostic Sciences, Animal Health Diagnostic Center, College of Veterinary Medicine, Cornell University

\section{Patrick K. Mitchell}

Department of Population Medicine and Diagnostic Sciences, Animal Health Diagnostic Center, College of Veterinary Medicine, Cornell University

\section{Thomas Cecere}

Department of Biomedical Sciences \& Pathobiology, Virginia-Maryland College of Veterinary Medicine, Virginia Tech

\section{Sandy Hancock}

Laboratory for Neurotoxicity Studies, Virginia-Maryland College of Veterinary Medicine, Virginia Tech

\section{Erin L. Goodrich}

Department of Population Medicine and Diagnostic Sciences, Animal Health Diagnostic Center, College of Veterinary Medicine, Cornell University

\section{Julia Murphy}

Virginia Department of Health, Division of Surveillance and Investigation

\section{Diego G. Diel ( $\nabla$ dgdiel@cornell.edu )}

Department of Population Medicine and Diagnostic Sciences, Animal Health Diagnostic Center, College of Veterinary Medicine, Cornell University

\section{Case Report}

Keywords: SARS-CoV-2, feline, transmission, HCM 
Posted Date: April 12th, 2021

DOl: https://doi.org/10.21203/rs.3.rs-406297/v1

License: (c) (i) This work is licensed under a Creative Commons Attribution 4.0 International License. Read Full License 


\section{Severe SARS-CoV-2 infection in a cat with hypertrophic cardiomyopathy}

Francisco R. Carvallo ${ }^{1 * \dagger}+$, Mathias Martins ${ }^{2} \uparrow$, Lok R. Joshi $^{2}$, Leonardo C. Caserta ${ }^{2}$, Patrick K. Mitchell $^{2}$, Thomas Cecere ${ }^{1}$, Sandy Hancock ${ }^{3}$, Erin L. Goodrich ${ }^{2}$, Julia Murphy ${ }^{4}$, Diego G. Diel ${ }^{2 *}$

${ }^{1}$ Department of Biomedical Sciences \& Pathobiology, Virginia-Maryland College of Veterinary Medicine, Virginia Tech, Blacksburg, VA, USA. Center, College of Veterinary Medicine, Cornell University, Ithaca, NY, USA.

${ }^{3}$ Laboratory for Neurotoxicity Studies, Virginia-Maryland College of Veterinary Medicine, Virginia Tech, Blacksburg, VA, USA.

${ }^{4}$ Virginia Department of Health, Division of Surveillance and Investigation, Richmond, VA, USA.

20

$\dagger$ These authors contributed equally to this work.

${ }^{2}$ Department of Population Medicine and Diagnostic Sciences, Animal Health Diagnostic Center, College of Veterinary Medicine, Cornell University; 240 Farrier Rd, AHDC A3-114, Ithaca, New York, USA.

*Corresponding author. Email: dgdiel@ cornell.edu 


\begin{abstract}
:
Coronavirus disease 19 (COVID-19), has claimed millions of human lives worldwide since the emergence of the zoonotic severe acute respiratory syndrome coronavirus 2 (SARS-CoV-2) in China in December 2019. Notably, most severe and fatal SARS-CoV-2 infections in humans have been associated with underlying clinical conditions, including diabetes, hypertension, and heart diseases. Here we describe a case of severe SARS-CoV-2 infection in a domestic cat (Felis catus) that presented with hypertrophic cardiomyopathy (HCM), a chronic heart condition that has been described as a comorbidity of COVID-19 in humans and that is prevalent in domestic cats. The lung and heart of the affected cat presented clear evidence of SARS-CoV-2 replication, with histological lesions similar to those observed in humans with COVID-19 with high infectious viral loads being recovered from these organs. The study highlights the potential impact of comorbidities on the outcome of SARS-CoV-2 infection in animals and provides important information that may contribute to the development of a feline model with the potential to recapitulate the clinical outcomes of severe COVID-19 in humans.
\end{abstract}

\title{
One-Sentence Summary:
}

Severe SARS-CoV-2 infection, resembling COVID-19 in humans in a cat with hypertrophic cardiomyopathy. 


\section{Main Text:}

Coronaviruses are associated with systemic, respiratory and/or enteric infections in humans and in livestock (cattle, horses, pigs, and poultry) and companion animals (dogs, cats and ferrets) (1). The members of the Coronaviridae are recognized for their ability to cross the species barrier and establish new host reservoirs of infection (2). The pandemic severe acute respiratory syndrome coronavirus 2 (SARS-CoV-2), which causes coronavirus disease 19 (COVID-19) in humans, has likely spilled over from bats to a yet unknown intermediate animal species and then to humans $(3,4)$. Interestingly, natural SARS-CoV-2 infections have been reported in dogs, cats, tigers, lions, snow lepards, a cugar, puma, gorillas, ferrets and farmed and wild caught mink (5-11). All animal cases have been shown to have an epidemiological link to confirmed human cases of COVID-19, suggesting human-to-animal transmission. Importantly, infections with SARS-CoV-2 in most animals have been associated with subclinical or mild respiratory distress.

In humans, most severe COVID-19 cases and deaths have been associated with underlying medical conditions, including cancer, kidney disease, chronic respiratory diseases, obesity, diabetes, and heart disease (such as heart failure, coronary artery disease or cardiomyopathies) (12). The association of underlying cardiovascular disease (CVD) and myocardial injury with severe and often fatal outcomes in COVID-19 patients has been well documented in humans $(13,14)$. However, the physio pathological mechanisms underlying these conditions and their contribution to the pathogenesis of severe COVID-19 are still under investigation.

Here we describe a case of severe respiratory and myocardial SARS-CoV-2 infection in a domestic cat (Felis catus), which suffered from hypertrophic cardiomyopathy (HCM), a common comorbidity of COVID-19 $(15,16)$. Virological and pathological findings demonstrated viral replication and virus associated lesions in multiple tissues and organs including lung and heart, an outcome that resembles multi-systemic involvement in severe cases of COVID-19 in humans.

In December 2020, a 4.5-year-old, $4.7 \mathrm{~kg}$ male castrated domestic medium hair cat presented to a veterinary clinic with a five-day long history of hyporexia and severe progressive 30 respiratory distress that was not responsive to therapy. Blood work revealed azotemia and hyperglycemia. Prior to this episode the cat had been diagnosed with a systolic II/IV (Faint but easily audible) heart murmur but received no medications. Due to poor prognosis and 
progressive disease severity, the owner elected to perform humane euthanasia. The animal was submitted to the Virginia Tech Animal Laboratory Services (ViTALS), Virginia Maryland College of Veterinary Medicine for diagnostic evaluation. The cat came from a household in which one person tested positive for SARS-CoV-2 by a rapid antigen-capture test $\sim 7$ days prior to the initiation of the clinical signs in the cat, while a second person in the household tested positive by real-time PCR $\sim 3-4$ days after the cat became ill.

At necropsy, a small amount of red tinged fluid was observed in the trachea. Approximately $15 \mathrm{~mL}$ of red tinged fluid was collected from the thorax. The lungs were diffusely mottled red and slightly firm, with patchy areas of depression of the parenchyma (Fig. 1A). Importantly, the left ventricular wall was moderately thickened, with a narrow ventricular cavity with the heart weighing approximately $22 \mathrm{~g}$. These observations suggested that the animal suffered from HCM, which was confirmed based on histological findings. Additionally, the liver was slightly pale with a prominent reticular pattern and the left kidney had a focal irregular chronic infarct of the cranial pole $(1 \mathrm{~cm}$ diameter $)$. No significant gross changes were observed 15 in other organs.

Given the clinical and pathological presentation, a complete diagnostic investigation, including viral and bacterial testing and histopathological evaluation, were performed. Respiratory specimens (nasal, tracheal and oropharyngeal swabs) and tissues were submitted to the Animal Health Diagnostic Center at Cornell University and initially subjected to PCR testing or culture for common feline respiratory pathogens (Bordetella sp., Chlamydia felis, Mycoplasma cynos, Mycoplasma felis, Streptococcus equi. ssp zooepidemicus, Influenza virus, pneumovirus, feline calicivirus and feline herpesvirus). The nasal swab sample tested positive for M. felis $(\mathrm{Ct}=32)$, while no other common feline pathogen was detected nor isolated. Additionally, bacterial culture on the lung tissue did not result in bacterial growth. Importantly, nasal oropharyngeal and rectal swabs were positive for SARS-CoV-2 when tested by real-time RT-PCR assay (rRT-PCR) (Fig. 1B). These results were confirmed at the National Veterinary Services Laboratory. Tissue samples including lung, heart, kidney, liver, spleen and intestine also tested positive for SARS-CoV-2 RNA by rRT-PCR (Fig. 1B). Higher viral loads, as evidenced by lower cycle threshold values, were detected in nasal, tracheal and oropharyngeal swabs and in the lung and heart (Fig. 1B).

Virus isolation and titrations performed in SARS-CoV-2 rRT-PCR positive samples revealed shedding of high amounts of infectious virus in respiratory secretions (titers between 
3.5 and $4.88 \log 10$ tissue culture infectious dose 50 [TCID 50$]$ per $\mathrm{mL}$ ) (Fig. 1C). Infectious virus was also detected in rectal swab samples (Fig. 1D). Virus isolation was confirmed using SARSCoV-2 specific polyclonal antibody against the $\mathrm{N}$ and $\mathrm{mAb}$ against $\mathrm{S} 2$ proteins (Fig. 1D). Additionally, high infectious viral loads were also detected in the lung and heart of the animal (Fig. 1B), suggesting active virus replication in these organs.

Tissues were also subjected to complete histopathological evaluations at the ViTALS. Examination of the trachea revealed focal areas of tracheal gland necrosis, with infiltrates of neutrophils and macrophages. In the lung, an acute bronchointerstitial pneumonia was noted (Fig. 2A and B). In the bronchi, there was circumferential degeneration and necrosis of bronchial epithelial cells, with focal infiltrates of viable and degenerate neutrophils and macrophages. Similar inflammatory infiltrates were present surrounding bronchial glands. Necrosis of epithelial cells and similar inflammation was identified in the bronchiolar lumen, with some being completely occluded with cellular debris (Fig. 2A). In alveoli, diffuse alveolar damage with vascular injury was noted, characterized by numerous macrophages with frequent

15 phagocytosis of cellular debris, presence of multinucleated cells suggesting syncytial cells and a few neutrophils (Fig. 2C and D), all immersed in edema, multifocal hemorrhages, and fibrin, with the formation of rare hyaline membranes. There was multifocal segmental hyperplasia of type II pneumocytes. The alveolar septa were thickened with increased numbers of intravascular neutrophils and multiple segments of necrotizing capillaritis, with microthrombi and focal dense infiltrates of neutrophils and macrophages (Fig. 2B). Occasional arteries had transmural infiltrates of mononuclear cells with margination of neutrophils. Most of the cells present in alveoli, particularly multinucleated cells, presented strong cytoplasmic immunoreactivity for Pan Cytokeratin (Fig. 2D, inset a). Most inflammatory cells infiltrating the tracheal glands and approximately one third of alveolar cells presented a strong cytoplasmic immunoreactivity for Iba-1, indicative of macrophages (Fig. 2B, inset a and 2D, inset b). Multifocal cluster of CD3 positive cells, indicative of T lymphocytes, were identified surrounding tracheal glands, bronchial glands, bronchioles, and blood vessels (data not shown). No B lymphocytes were highlighted with CD79a stain in the analyzed sections of lung or trachea. Importantly, in situ hybridization (ISH) for SARS-CoV-2 RNA and immunohistochemistry (IHC) staining revealed strong viral labeling/immunoreactivity in bronchial epithelial cells, bronchiolar glands, bronchiolar epithelium and in few desquamated epithelial cells/macrophages in alveolar spaces (Fig. 3). 
In the heart, there were multifocal to coalescing areas of degeneration and necrosis of cardiomyocytes, with cells displaying hypereosinophilic cytoplasm, loss of striations, hyper contraction bands, vacuolation and or pyknotic nuclear debris (Fig. 4A). There was edema with the presence of small numbers of macrophages and neutrophils between myofibers (Fig. 4A). In addition, there was mild concentric hypertrophy of the left ventricle. Cardiomyocytes have moderate variation of the cytoplasmic diameter, a feature that was more frequent towards the periphery of the myocardium. In addition to virus isolation, electron microscopy (EM) examination of the heart revealed multiple coronavirus like particles in endothelial cells within the ventricular myocardium. The viral particles were evident within cisternae of the endoplasmic reticulum, in membrane bound vesicles adjacent to the inner surface of the plasma membrane, or adjacent to ribosomes and cytosolic debris in cells with autolytic change. Virus particles were composed of an outer double membrane and a core consisting of multiple, variably distinct, electron dense punctate dots (nucleocapsid) (Fig. 4B).

In the mesenteric lymph node, there was abundant fibrin, multifocal hemorrhages and small numbers of foamy macrophages within the subcapsular sinuses. There was marked congestion of the cortex, with edema and occasional necrotic cellular debris in lymphoid germinal centers (not shown). No significant findings were identified in other internal organs examined.

The complete genome sequence of SARS-CoV-2 was obtained directly from the respiratory secretions (nasal, tracheal and oropharyngeal secretions) and feces from the affected cat. When compared to the Wuhan-Hu-1, the SARS-CoV-2 virus recovered from the cat in the present study presented 14 single nucleotide polymorphisms (SNPs). Lineage prediction using pangolin https://github.com/cov-lineages/pangolin/blob/master/github.com/covlineages/pangolin) (17-22) identified the sequence as belonging to SARS-CoV-2 lineage B.1.240 which comprises a total of 2033 sequences in the GISAID dataset (accessed 2021-03-25).

The sequence identified in the cat clustered with human SARS-CoV-2 sequences detected in Virginia or in nearby states. Phylogenetic analysis using Nextstrain (23) placed two SNPs, both encoding amino acid changes (A15659G, ORF1b: D731G; C29376T, N: P368L) on the terminal branch leading to the sequence from the cat. One SNP downstream of the parent node of the cat sequence was a group of 36 sequences from the Pacific Northwest (Oregon and Washington) while moving 1 SNP upstream to the next ancestor node added 17 sequences including 10 from Virginia (Fig. S1). Unfortunately, no SARS-CoV-2 sequences were recovered 
from rRT-PCR positive samples from the cat owners who tested positive for SARS-CoV-2. Therefore, it was not possible to establish a direct link between the virus recovered from the affected animal and the first person diagnosed prior to the animal or second the second person who tested positive for SARS-CoV-2 after the cat became clinical.

Human to animal transmission and natural infections with SARS-CoV-2 have been reported in domestic cats, dogs, ferrets and mink $(5,9,24,25)$ as well as in wild animals in zoological collections around the world including tigers, lions and puma (7)(26) . Most SARSCoV-2 infections in animals have been associated with subclinical- or only with mild clinical signs in affected animals (26-29). Interestingly, among the companion animals with confirmed SARS-CoV-2 infections reported around the world to date, 13 animals died or were euthanized (10 in the US, 2 in Spain and 1 in Brazil) following detection of the virus (including the domestic cat described here) $(25,26,30)$. The role of SARS-CoV-2 in the deaths of these animals (eight dogs and six cats) remains largely unknown, however, all animals that died had underlying clinical conditions or comorbidities, including chronic lung disease, several types of cancers, and 15 heart diseases $(25,26,30)$, which is similar to what has been described in humans with severe COVID-19.

The case described here presents striking similarities (clinical, virological and pathological) with severe cases of COVID-19 in humans $(31,32)$. Clinically the animal presented severe progressive respiratory distress for 5-6 days and was non-responsive to supportive therapy. Additionally, high viral loads (viral RNA and infectious virus) were detected in upper (nasal and oropharyngeal swabs) and lower (tracheal swab) respiratory secretions and in the lung and heart of the affected cat. In humans, gross lung pathology is usually overlaid by chronic diseases such as chronic bronchitis and emphysema (33) and include heavy, congested and edematous lung, with patchy to diffuse areas of consolidation and occasional arterial 25 thrombosis (33-35). These lesions are similar to the gross findings observed in the lung of the cat in this study, however, no evidence of underlying chronic condition was found in the lung of the animal.

The predominant histologic pulmonary lesion in human patients that develop pneumonia due to the infection with SARS-CoV-2 is diffuse alveolar damage (DAD), including the exudative, proliferative and fibrotic phases or a mixture of these, with various levels of progression and severity. Changes include edema, congestion and formation of hyaline membranes, hyperplasia of atypical type II pneumocytes (reactive atypia) and increased numbers 
of macrophages and lesser neutrophils in the alveolar lumen; interstitial thickening with vascular thrombosis, CD4+ and CD8+ lymphocytes and macrophages infiltrates and variable interstitial proliferation of myofibroblasts (33-37). Similar to the findings in humans, the histological changes observed in the lung of the cat in this study are indicative of DAD, with proliferation of atypical type II pneumocytes (reactive atypia), thrombosis and focal areas of capillaritis and the inflammatory infiltrate being mainly composed of neutrophils and macrophages, which support an early disease stage. An observation that was confirmed by virus isolation, IHC and ISH, demonstrating active viral replication and suggesting direct viral damage to the lung.

A characteristic of SARS-CoV-2 infection in humans, is the broad organotropism of the virus which can be detected not only in the lung but also in other vital organs such as heart, liver, brain and kidneys (38). In the cat reported here, SARS-CoV-2 RNA was detected by rRT-PCR in the lung, heart, kidney, liver, spleen, and intestine with high amounts of infectious virus being recovered from lung and heart of the animal. Reported histological findings on the human heart are variable and range from no lesions to a few interstitial mononuclear inflammatory infiltrates $(37,39)$ to myocardial degeneration and necrosis without significant inflammation $(36,40)$. Histological examination of the heart of the cat in this study revealed acute myocardial degeneration and necrosis, with mild interstitial acute inflammation. These observations are compatible with an early manifestation of viral myocarditis but could also be secondary to a disseminated vascular damage. Recovery of high amounts of infectious virus from the heart and visualization of viral particles in the tissue by EM, would support viral induced myocarditis.

One of the most intriguing findings of this study was the fact that the animal was affected by HCM, as evidenced at necropsy by an enlarged ventricular wall and a narrow left ventricle. The association of underlying cardiovascular disease (CVD) and myocardial injury with severe and often fatal outcomes of COVID-19 in human patients has been well documented (13). A study exploring the myocardial transcriptomic differences between humans with hypertrophic cardiomyopathy (HCM) and healthy control donors, revealed that ACE2 was the most up-regulated gene in HCM hearts, and showed a 5-fold overexpression of ACE2 protein (16). The authors suggest that this increased ACE2 expression in the heart could be associated with an increased risk for severe COVID-19 manifestations in HCM patients (16). Whether increased levels of ACE2 are expressed in the heart of domestic cats presenting with HCM and whether this condition represents a risk factor to severe disease due to SARS-CoV-2 infection in domestic cats remains to be investigated. However, the fact that HCM has been observed as a 
comorbidity in other cats diagnosed with SARS-CoV-2 and that presented severe progressive respiratory disease $(30,41)$ support the hypothesis that this common heart condition in cats could potentially predispose severe disease and poor prognosis in domestic cats that become infected with SARS-CoV-2. The clinical, pathological and viral findings on the cat studied here aligns with the algorithm recently developed by CDC (30), implicating SARS-CoV-2 with the severe disease outcome that led to humane euthanasia of the animal.

\section{References and Notes}

1. S. Masters, Paul s., Perlman, CHAPTER 28 - Coronaviridae. Fields Virol. 6th Ed. (2013).

2. R. L. Graham, R. S. Baric, Recombination, Reservoirs, and the Modular Spike: Mechanisms of Coronavirus Cross-Species Transmission. J. Virol. (2010), doi:10.1128/jvi.01394-09.

3. S. Murakami, T. Kitamura, J. Suzuki, R. Sato, T. Aoi, M. Fujii, H. Matsugo, H. Kamiki, H. Ishida, A. Takenaka-Uema, M. Shimojima, T. Horimoto, Detection and Characterization of Bat Sarbecovirus Phylogenetically Related to SARS-CoV-2, Japan. Emerg. Infect. Dis. (2020), doi:10.3201/eid2612.203386.

4. S. K. P. Lau, H. K. H. Luk, A. C. P. Wong, K. S. M. Li, L. Zhu, Z. He, J. Fung, T. T. Y. Chan, K. S. C. Fung, P. C. Y. Woo, Possible Bat Origin of Severe Acute Respiratory Syndrome Coronavirus 2. Emerg. Infect. Dis. 26, 1542-1547 (2020).

5. T. H. C. Sit, C. J. Brackman, S. M. Ip, K. W. S. Tam, P. Y. T. Law, E. M. W. To, V. Y. T. Yu, L. D. Sims, D. N. C. Tsang, D. K. W. Chu, R. A. P. M. Perera, L. L. M. Poon, M. Peiris, Infection of dogs with SARS-CoV-2. Nature (2020), doi:10.1038/s41586-0202334-5.

6. N. Oreshkova, R. J. Molenaar, S. Vreman, F. Harders, B. B. Oude Munnink, R. W. H. Van Der Honing, N. Gerhards, P. Tolsma, R. Bouwstra, R. S. Sikkema, M. G. J. Tacken, M. M. T. De Rooij, E. Weesendorp, M. Y. Engelsma, C. J. M. Bruschke, L. A. M. Smit, M. Koopmans, W. H. M. Van Der Poel, A. Stegeman, SARS-CoV-2 infection in farmed minks, the Netherlands, April and May 2020. Eurosurveillance. 25 (2020), doi:10.2807/1560-7917.ES.2020.25.23.2001005.

7. D. McAloose, M. Laverack, L. Wang, M. L. Killian, L. C. Caserta, F. Yuan, P. K. Mitchell, K. Queen, M. R. Mauldin, B. D. Cronk, S. L. Bartlett, J. M. Sykes, S. Zec, T. Stokol, K. Ingerman, M. A. Delaney, R. Fredrickson, M. Ivančić, M. Jenkins-Moore, K. Mozingo, K. Franzen, N. H. Bergeson, L. Goodman, H. Wang, Y. Fang, C. Olmstead, C. McCann, P. Thomas, E. Goodrich, F. Elvinger, D. C. Smith, S. Tong, S. Slavinski, P. P. Calle, K. Terio, M. K. Torchetti, D. G. Diel, From people to panthera: Natural sars-cov-2 infection in tigers and lions at the bronx zoo. MBio. 11, 1-13 (2020).

8. N. York, M. April, A. N. Dvm, D. Smith, R. R. Ghai, R. M. Wallace, M. K. Torchetti, C. Loiacono, First Reported Cases of SARS-CoV-2 Infection in Companion Animals - . 69, 
$710-713$ (2020).

9. C. Gortázar, S. Barroso-Arévalo, E. Ferreras-Colino, J. Isla, G. de la Fuente, B. Rivera, L. Domínguez, J. de la Fuente, J. M. Sánchez-Vizcaíno, Natural SARS-CoV-2 infection in kept ferrets, Spain. bioRxiv (2021).

10. S. A. Shriner, J. W. Ellis, J. J. Root, A. Roug, S. R. Stopak, G. W. Wiscomb, J. R. Zierenberg, H. S. Ip, M. K. Torchetti, T. J. DeLiberto, SARS-CoV-2 exposure in escaped mink, Utah, USA. Emerg. Infect. Dis. 27, 988-990 (2021).

11. USDA APHIS | Confirmation of COVID-19 in a Snow Leopard at a Kentucky Zoo, (available at https://www.aphis.usda.gov/aphis/newsroom/stakeholder-info/sa_by_date/sa2020/sa-12/ky-snow-leopard-covid).

12. A. Banerjee, L. Pasea, S. Harris, A. Gonzalez-Izquierdo, A. Torralbo, L. Shallcross, M. Noursadeghi, D. Pillay, N. Sebire, C. Holmes, C. Pagel, W. K. Wong, C. Langenberg, B. Williams, S. Denaxas, H. Hemingway, Estimating excess 1-year mortality associated with the COVID-19 pandemic according to underlying conditions and age: a population-based cohort study. Lancet (2020), doi:10.1016/S0140-6736(20)30854-0.

13. T. Guo, Y. Fan, M. Chen, X. Wu, L. Zhang, T. He, H. Wang, J. Wan, X. Wang, Z. Lu, Cardiovascular Implications of Fatal Outcomes of Patients with Coronavirus Disease 2019 (COVID-19). JAMA Cardiol. (2020), doi:10.1001/jamacardio.2020.1017.

14. R. M. Inciardi, M. Adamo, L. Lupi, D. S. Cani, M. Di Pasquale, D. Tomasoni, L. Italia, G. Zaccone, C. Tedino, D. Fabbricatore, A. Curnis, P. Faggiano, E. Gorga, C. M. Lombardi, G. Milesi, E. Vizzardi, M. Volpini, S. Nodari, C. Specchia, R. Maroldi, M. Bezzi, M. Metra, Characteristics and outcomes of patients hospitalized for COVID-19 and cardiac disease in Northern Italy. Eur. Heart J. (2020), doi:10.1093/eurheartj/ehaa388.

15. G. Limongelli, G. Limongelli, G. Limongelli, G. Limongelli, L. Crotti, L. Crotti, L. Crotti, L. Crotti, COVID-19 pandemia and inherited cardiomyopathies and channelopathies: A short term and long term perspective. Orphanet J. Rare Dis. 15, 157 (2020).

16. J. M. Bos, V. B. Hebl, A. L. Oberg, Z. Sun, D. S. Herman, P. Teekakirikul, J. G. Seidman, C. E. Seidman, C. G. dos Remedios, J. J. Maleszewski, H. V. Schaff, J. A. Dearani, P. A. Noseworthy, P. A. Friedman, S. R. Ommen, F. V. Brozovich, M. J. Ackerman, Marked Up-Regulation of ACE2 in Hearts of Patients With Obstructive Hypertrophic Cardiomyopathy: Implications for SARS-CoV-2-Mediated COVID-19. Mayo Clin. Proc. 95, 1354-1368 (2020).

17. L. T. Nguyen, H. A. Schmidt, A. Von Haeseler, B. Q. Minh, IQ-TREE: A fast and effective stochastic algorithm for estimating maximum-likelihood phylogenies. Mol. Biol. Evol. 32, 268-274 (2015).

18. D. T. Hoang, O. Chernomor, A. Von Haeseler, B. Q. Minh, L. S. Vinh, UFBoot2: Improving the ultrafast bootstrap approximation. Mol. Biol. Evol. 35, 518-522 (2018).

19. S. Guindon, J.-F. Dufayard, V. Lefort, M. Anisimova, W. Hordijk, O. Gascuel, New 
Algorithms and Methods to Estimate Maximum-Likelihood Phylogenies: Assessing the Performance of PhyML 3.0. Syst. Biol. 59, 307-321 (2010).

20. K. Katoh, D. M. Standley, MAFFT multiple sequence alignment software version 7: Improvements in performance and usability. Mol. Biol. Evol. 30, 772-780 (2013).

21. H. Li, Minimap2: Pairwise alignment for nucleotide sequences. Bioinformatics. 34, 30943100 (2018).

22. J. Koster, S. Rahmann, Snakemake--a scalable bioinformatics workflow engine. Bioinformatics. 28, 2520-2522 (2012).

23. J. Hadfield, C. Megill, S. M. Bell, J. Huddleston, B. Potter, C. Callender, P. Sagulenko, T. Bedford, R. A. Neher, Nextstrain: real-time tracking of pathogen evolution.

Bioinformatics. 34, 4121-4123 (2018).

24. E. I. Patterson, G. Elia, A. Grassi, A. Giordano, C. Desario, M. Medardo, S. L. Smith, E. R. Anderson, T. Prince, G. T. Patterson, E. Lorusso, M. S. Lucente, G. Lanave, S. Lauzi, U. Bonfanti, A. Stranieri, V. Martella, F. Solari Basano, V. R. Barrs, A. D. Radford, U. Agrimi, G. L. Hughes, S. Paltrinieri, N. Decaro, Evidence of exposure to SARS-CoV-2 in cats and dogs from households in Italy. Nat. Commun. 11, 1-5 (2020).

25. J. Segalés, M. Puig, J. Rodon, C. Avila-Nieto, J. Carrillo, G. Cantero, M. T. Terrón, S. Cruz, M. Parera, M. Noguera-Julián, N. Izquierdo-Useros, V. Guallar, E. Vidal, A. Valencia, I. Blanco, J. Blanco, B. Clotet, J. Vergara-Alert, Detection of SARS-CoV-2 in a cat owned by a COVID-19-affected patient in Spain. Proc. Natl. Acad. Sci. U. S. A. 117, 24790-24793 (2020).

26. Events in animals: OIE - World Organisation for Animal Health, (available at https://www.oie.int/en/scientific-expertise/specific-information-andrecommendations/questions-and-answers-on-2019novel-coronavirus/events-in-animals/).

27. J. Shi, Z. Wen, G. Zhong, H. Yang, C. Wang, B. Huang, R. Liu, X. He, L. Shuai, Z. Sun, Y. Zhao, P. Liu, L. Liang, P. Cui, J. Wang, X. Zhang, Y. Guan, W. Tan, G. Wu, H. Chen, Z. Bu, Susceptibility of ferrets, cats, dogs, and other domesticated animals to SARScoronavirus 2. Science (80-. ). 368, 1016-1020 (2020).

28. A. Chandrashekar, J. Liu, A. J. Martino, K. McMahan, N. B. Mercad, L. Peter, L. H. Tostanosk, J. Yu, Z. Maliga, M. Nekorchuk, K. Busman-Sahay, M. Terry, L. M. Wriji, S. Ducat, D. R. Martine, C. Atyeo, S. Fischinger, J. S. Burk, M. D. Slei, L. Pessaint, A. Van Ry, J. Greenhouse, T. Taylor, K. Blade, A. Cook, B. Finneyfrock, R. Brown, E. Teow, J. Velasco, R. Zahn, F. Wegmann, P. Abbink, E. A. Bondzi, G. Dagotto, M. S. Gebr, X. He, C. Jacob-Dolan, N. Kordana, Z. Li, M. A. Lifto, S. H. Mahrokhia, L. F. Maxfiel, R. Nityanandam, J. P. Nkolol, A. G. Schmid, A. D. Mille, R. S. Bari, G. Alter, P. K. Sorge, J. D. Este, H. Andersen, M. G. Lewi, D. H. Barou, SARS-CoV-2 infection protects against rechallenge in rhesus macaques. Science (80-. ). (2020), doi:10.1126/science.abc4776.

29. V. J. Munster, F. Feldmann, B. N. Williamson, N. van Doremalen, L. Pérez-Pérez, J. Schulz, K. Meade-White, A. Okumura, J. Callison, B. Brumbaugh, V. A. Avanzato, R. 
Rosenke, P. W. Hanley, G. Saturday, D. Scott, E. R. Fischer, E. de Wit, Respiratory disease in rhesus macaques inoculated with SARS-CoV-2. Nature. 585, 268-272 (2020).

30. A. Carpenter, R. Ghai, J. Gary, J. Ritter, F. Carvallo, D. G. Diel, M. Martins, J. Murphy, B. Schroeder, K. Brightbill, L. Tewari, Deepanker Boger, J. Gabel, J. Cobb, Robert Hennebelle, Y.-Y. C. Stanton, James McCullough, Kathryn Mosley, R. Radcliff, B. Parr, G. Balsamo, B. Robbins, D. Smith, S. Slavinski, C. Williams, D. Meckes, D. Jones, T. Frazier, J. Rooney, M. Torchetti, N. Wendling, D. Currie, R. Barton Behravesh, Casey Wallace, Role of Naturally Acquired SARS-CoV-2 Infection in the Deaths of Ten Domestic Pets in the United States. Submitt. Sci.

31. Y. Liu, L. M. Yan, L. Wan, T. X. Xiang, A. Le, J. M. Liu, M. Peiris, L. L. M. Poon, W. Zhang, Viral dynamics in mild and severe cases of COVID-19. Lancet Infect. Dis. (2020), , doi:10.1016/S1473-3099(20)30232-2.

32. D. A. Dorward, C. D. Russell, I. H. Um, M. Elshani, S. D. Armstrong, R. Penrice-Randal, T. Millar, C. E. B. Lerpiniere, G. Tagliavini, C. S. Hartley, N. P. Randle, N. N. Gachanja, P. M. D. Potey, X. Dong, A. M. Anderson, V. L. Campbell, A. J. Duguid, W. Al Qsous, R. BouHaidar, J. Kenneth Baillie, K. Dhaliwal, W. A. Wallace, C. O. C. Bellamy, S. Prost, C. Smith, J. A. Hiscox, D. J. Harrison, C. D. Lucas, Tissue-specific immunopathology in fatal COVID-19. Am. J. Respir. Crit. Care Med. (2021), doi:10.1164/rccm.202008$32650 C$.

33. C. Edler, A. S. Schröder, M. Aepfelbacher, A. Fitzek, A. Heinemann, F. Heinrich, A. Klein, F. Langenwalder, M. Lütgehetmann, K. Meißner, K. Püschel, J. Schädler, S. Steurer, H. Mushumba, J. P. Sperhake, Dying with SARS-CoV-2 infection-an autopsy study of the first consecutive 80 cases in Hamburg, Germany. Int. J. Legal Med. 134, 1275-1284 (2020).

34. A. C. Borczuk, S. P. Salvatore, S. V. Seshan, S. S. Patel, J. B. Bussel, M. Mostyka, S. Elsoukkary, B. He, C. Del Vecchio, F. Fortarezza, F. Pezzuto, P. Navalesi, A. Crisanti, M. E. Fowkes, C. H. Bryce, F. Calabrese, M. B. Beasley, COVID-19 pulmonary pathology: a multi-institutional autopsy cohort from Italy and New York City. Mod. Pathol. 33, 21562168 (2020).

35. S. Damiani, M. Fiorentino, A. De Palma, M. P. Foschini, T. Lazzarotto, L. Gabrielli, P. L. Viale, L. Attard, M. Riefolo, A. D’Errico, Pathological post-mortem findings in lungs infected with <scp>SARS-CoV-2</scp>. J. Pathol. 253, 31-40 (2021).

36. S. E. Fox, A. Akmatbekov, J. L. Harbert, G. Li, J. Quincy Brown, R. S. Vander Heide, Pulmonary and cardiac pathology in African American patients with COVID-19: an autopsy series from New Orleans. Lancet Respir. Med. 8, 681-686 (2020).

37. R. B. Martines, J. M. Ritter, E. Matkovic, J. Gary, B. C. Bollweg, H. Bullock, C. S. Goldsmith, L. Silva-Flannery, J. N. Seixas, S. Reagan-Steiner, T. Uyeki, A. Denison, J. Bhatnagar, W. J. Shieh, S. R. Zaki, R. Cole, A. Lewis, P. Fair, L. Estetter, Pathology and pathogenesis of SARS-CoV-2 associated with fatal coronavirus disease, united states. Emerg. Infect. Dis. 26, 2005-2015 (2020). 
38. V. G. Puelles, M. Lütgehetmann, M. T. Lindenmeyer, J. P. Sperhake, M. N. Wong, L. Allweiss, S. Chilla, A. Heinemann, N. Wanner, S. Liu, F. Braun, S. Lu, S. Pfefferle, A. S. Schröder, C. Edler, O. Gross, M. Glatzel, D. Wichmann, T. Wiech, S. Kluge, K. Pueschel, M. Aepfelbacher, T. B. Huber, Multiorgan and Renal Tropism of SARS-CoV-2. N. Engl. J. Med. 383, 590-592 (2020).

39. Z. Xu, L. Shi, Y. Wang, J. Zhang, L. Huang, C. Zhang, S. Liu, P. Zhao, H. Liu, L. Zhu, Y. Tai, C. Bai, T. Gao, J. Song, P. Xia, J. Dong, J. Zhao, F. S. Wang, Pathological findings of COVID-19 associated with acute respiratory distress syndrome. Lancet Respir. Med. 8, 420-422 (2020).

40. L. M. Buja, D. Wolf, B. Zhao, B. Akkanti, M. McDonald, L. Lelenwa, N. Reilly, G. Ottaviani, M. T. Elghetany, D. O. Trujillo, G. M. Aisenberg, M. Madjid, B. Kar, The emerging spectrum of cardiopulmonary pathology of the coronavirus disease 2019 (COVID-19): Report of 3 autopsies from Houston, Texas, and review of autopsy findings from other United States cities. Cardiovasc. Pathol. 48 (2020), doi:10.1016/j.carpath.2020.107233.

41. J. Segalés, M. Puig, J. Rodon, C. Avila-Nieto, J. Carrillo, G. Cantero, M. Teresa Terrón, S. Cruz, M. Parera, M. Noguera-Julián, N. Izquierdo-Useros, V. Guallar, E. Vidal, A. Valencia, I. Blanco, J. Blanco, B. Clotet, J. Vergara-Alert, Detection of SARS-CoV-2 in a cat owned by a COVID-19-affected patient in Spain, doi:10.1073/pnas.2010817117. 
Acknowledgments: We would like to thank the Molecular Diagnostics Laboratory at Cornell AHDC staff for performing the feline panel and SARS-CoV-2 testing on the initial respiratory samples.

\section{Funding:}

Cornell Feline Health Center, as part of the Rapid Response Funds program.

\section{Author contributions:}

Conceptualization: FRC, MM, DGD

Methodology: FRC, MM, LRJ, LCC, PKM, TC, SH, DGD

Investigation: FRC, MM, ELG, JM, DGD

Visualization: FRC, MM, LRJ

Funding acquisition: DGD

Project administration: FRC, DGD

Writing - original draft: FRC, MM, LRJ, DGD

Writing - review \& editing: FRC, MM, LRJ, LCC, PKM, TC, ELG, SH, JM, DGD

Competing interests: Authors declare that they have no competing interests.

Data and materials availability: All data are available in the main text or the supplementary materials. Whole genome sequences of the SARS-CoV-2 recovered from the cat were deposited on GenBank (accession no. MW856303). 


\section{Supplementary Materials}

Materials and Methods

10 Figs. S1

Table S1-S2

References 

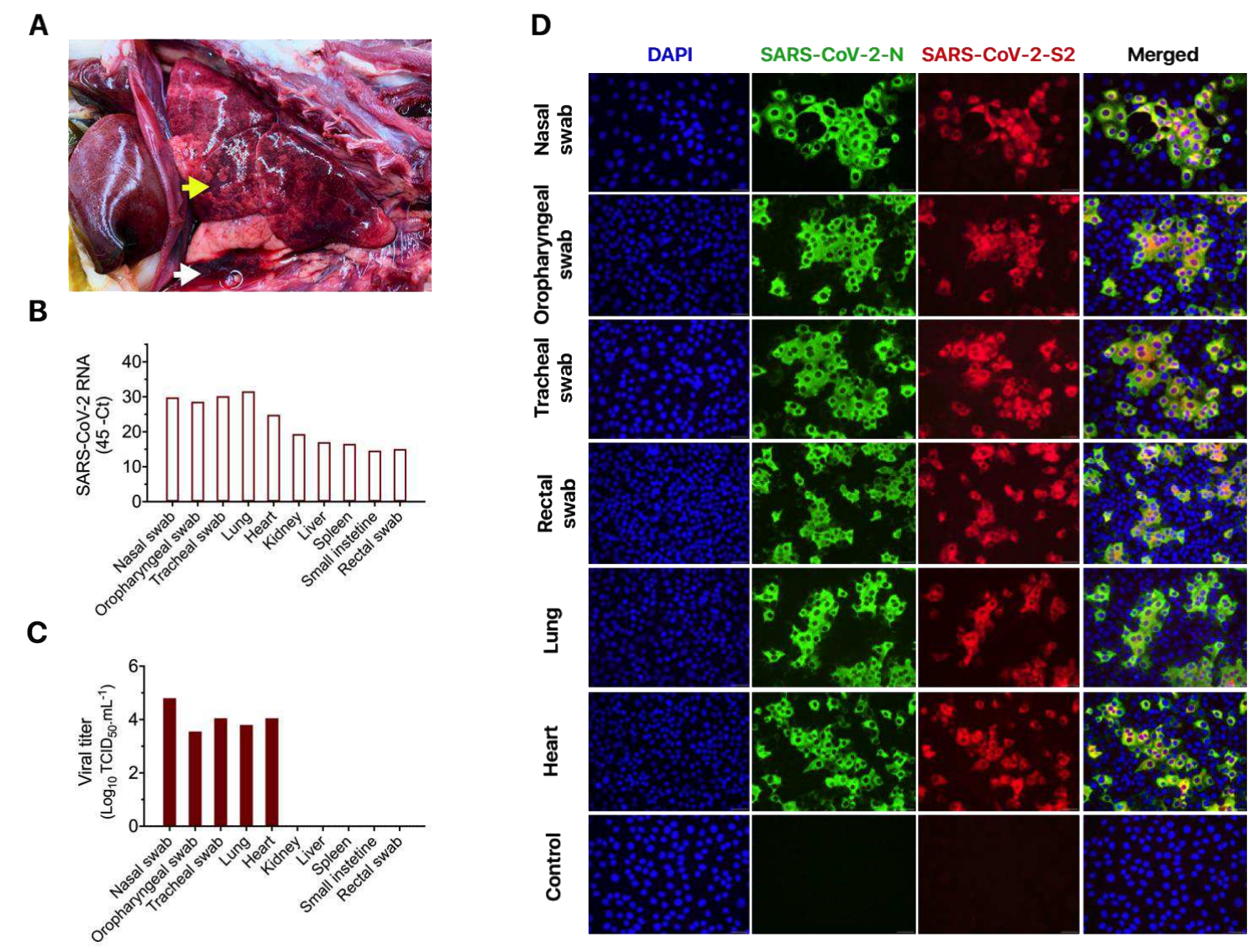

Fig. 1. Gross pathological and virological findings in a domestic cat presenting progressive respiratory disease. (A) Lungs are mottled red with focal depressed areas in the parenchyma (yellow arrow). A red tinged fluid is present in the thoracic cavity (white arrow). (B) Viral loads detected in respiratory secretions, feces and in lung, heart, kidney, spleen and intestine as

10 determined by real-time RT-PCR. (C) Viral titers in respiratory secretions, in lung and heart as determined using end-point dilutions and the Spearman and Karber's method and expressed as $\mathrm{TCID}_{50} \cdot \mathrm{mL}^{-1}$. (D) Virus isolation was confirmed by immunofluorescence. For this, Vero E6/TMPRSS2 cells were inoculated with cell lysate of virus isolation assays performed in respiratory secretions, feces, lung, and heart tissue homogenate. At $24 \mathrm{~h}$ post-inoculation cells 15 were fixed and subjected to an immunofluorescence assay using a polyclonal antibody antiSARS-CoV-2-nucleoprotein (N) (green), a mAb anti-SARS-CoV-2-Spike protein S2 subunit (red), and the nuclear counterstain performed with DAPI (blue). This confirmed isolation of SARS-CoV-2 from nasal secretions, oropharyngeal and tracheal secretions, feces and from the lungs and heart of the cat. $40 \mathrm{X}$ magnification. 


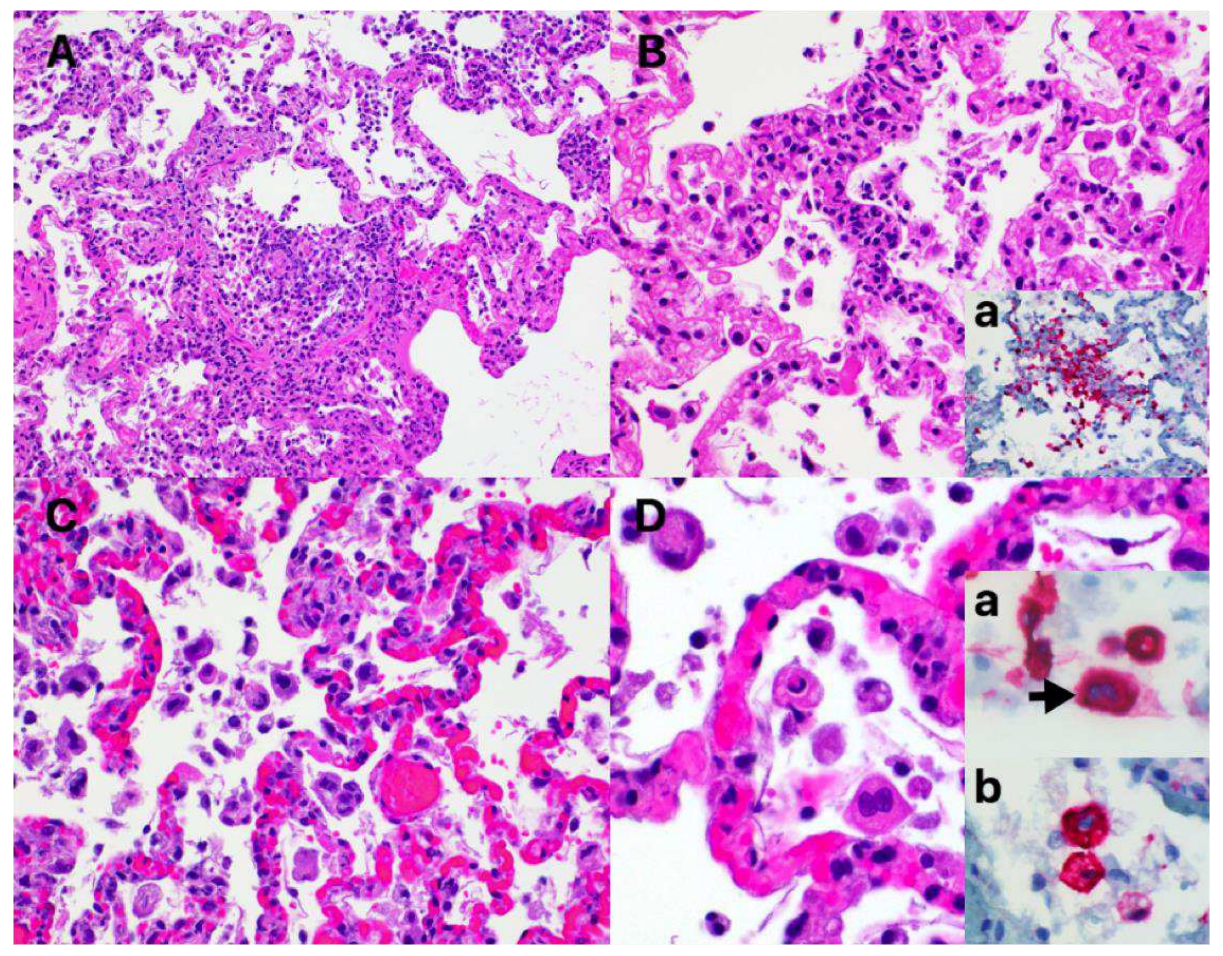

Fig. 2. Histological changes in the lung of the SARS-CoV-2 infected cat. (A) Necrotizing bronchiolitis and diffuse alveolar damage (DAD), with a partially occluded bronchiole with necrotic cellular debris and inflammatory cells. Adjacent alveolar spaces contain increased cellularity, mild edema and fibrin strands, and the interstitium is expanded with numerus 15 inflammatory cells. Hematoxylin and eosin. 20X magnification. (B) Capilaritis. Alveolar septa are infiltrated with neutrophils and macrophages. A fibrin thrombus is identified adjacent to the area of inflammation (arrow). Hematoxylin and eosin. Inset a. Iba-1 immunohistochemistry of an area of capillaritis, highlighting the presence of numerous macrophages. Mayer's hematoxylin counterstain. 40X magnification. (C) Alveolar spaces containing increased numbers of 20 mononuclear cells and necrotic cellular debris. The alveolar septa are markedly congested with increased numbers of neutrophils and macrophages. Hematoxylin and eosin. 20X magnification. (D) Reactive atypia. Cells present in alveolar spaces, with abundant eosinophilic cytoplasm and moderately enlarged nucleus. Hematoxylin and eosin. 40X magnification. Inset a. Pancytokeratin immunohistochemistry of alveolar cells, indicative of epithelial cells. One binucleated cell is noted (syncytium, arrow). Mayer's hematoxylin counterstain. Inset b. Iba-1 immunohistochemistry of alveolar cells, indicative of macrophages. Mayer's hematoxylin counterstain. 40X magnification. 
A
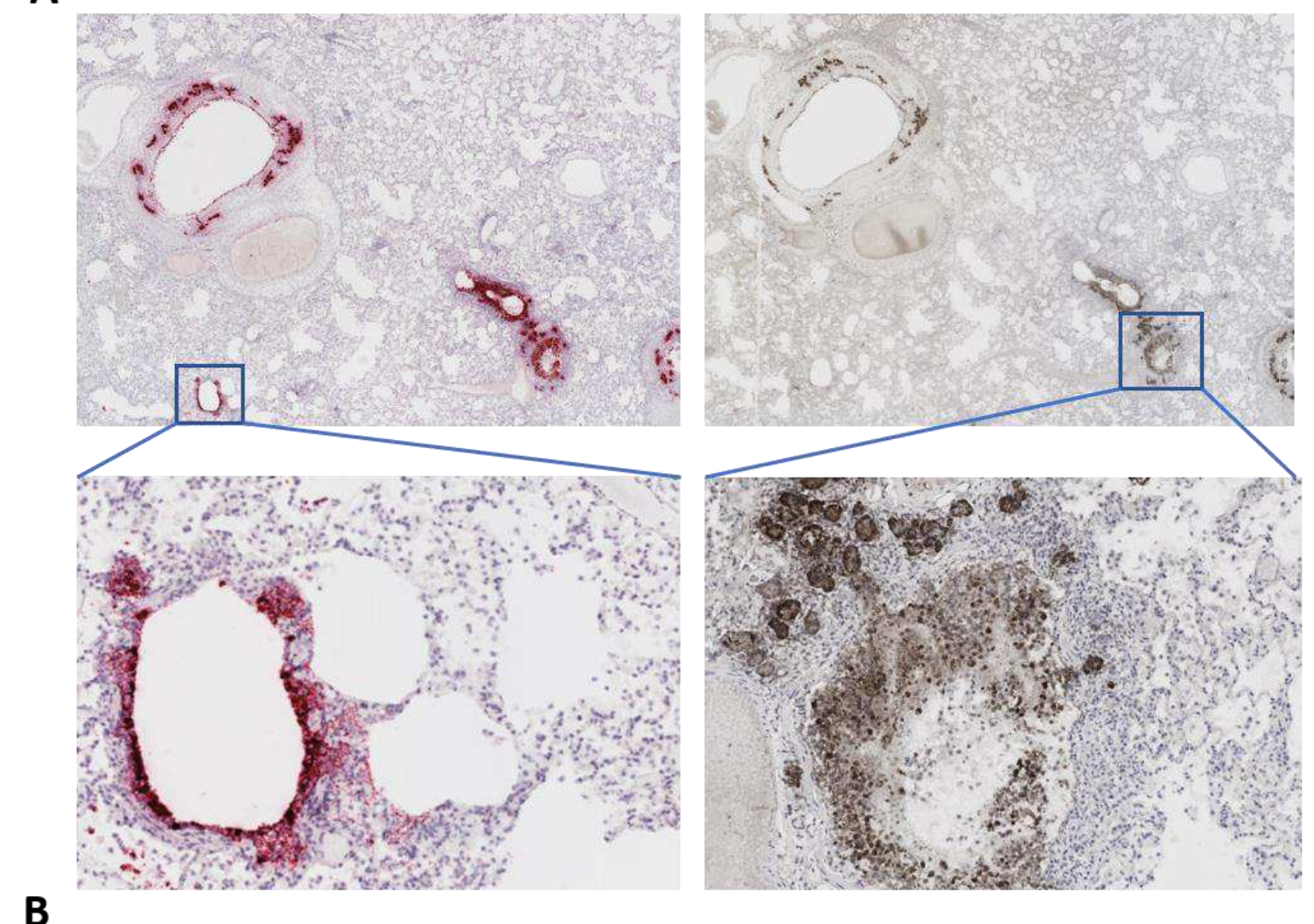

B
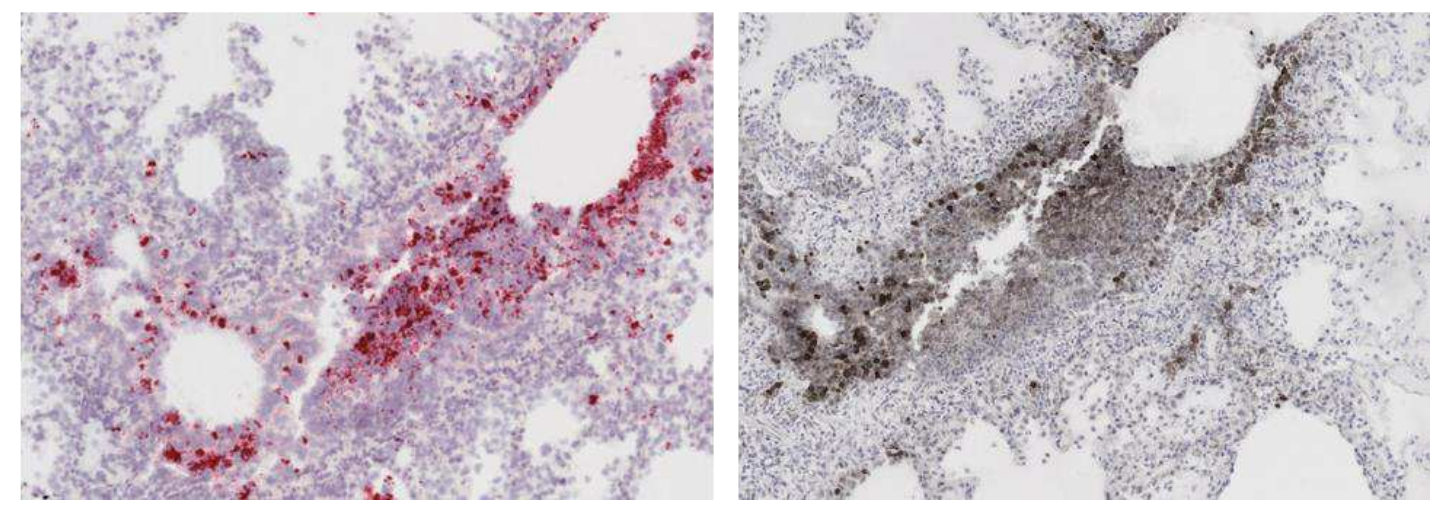

Fig. 3. SARS-CoV-2 labeling in the lung of the affected cat. (A) In situ hybridization (ISH) (left panels) showing labeling (pink/reddish labeling) for SARS-CoV-2 RNA in bronchial and bronchiolar epithelial cells and bronchial glands. Immunohistochemistry (IHC) (right panels) showing staining for the SARS-CoV-2 N protein (brown stain) in bronchial and bronchiolar epithelial cells and bronchial glands. Tissue section were counter stained with hematoxylin. (B) ISH and IHC performed in the same section demonstrating co-localization of viral RNA labeling (pink/reddish) and viral protein $(\mathrm{N})$, indicating active SARS-CoV-2 replication in the lung of the cat. 

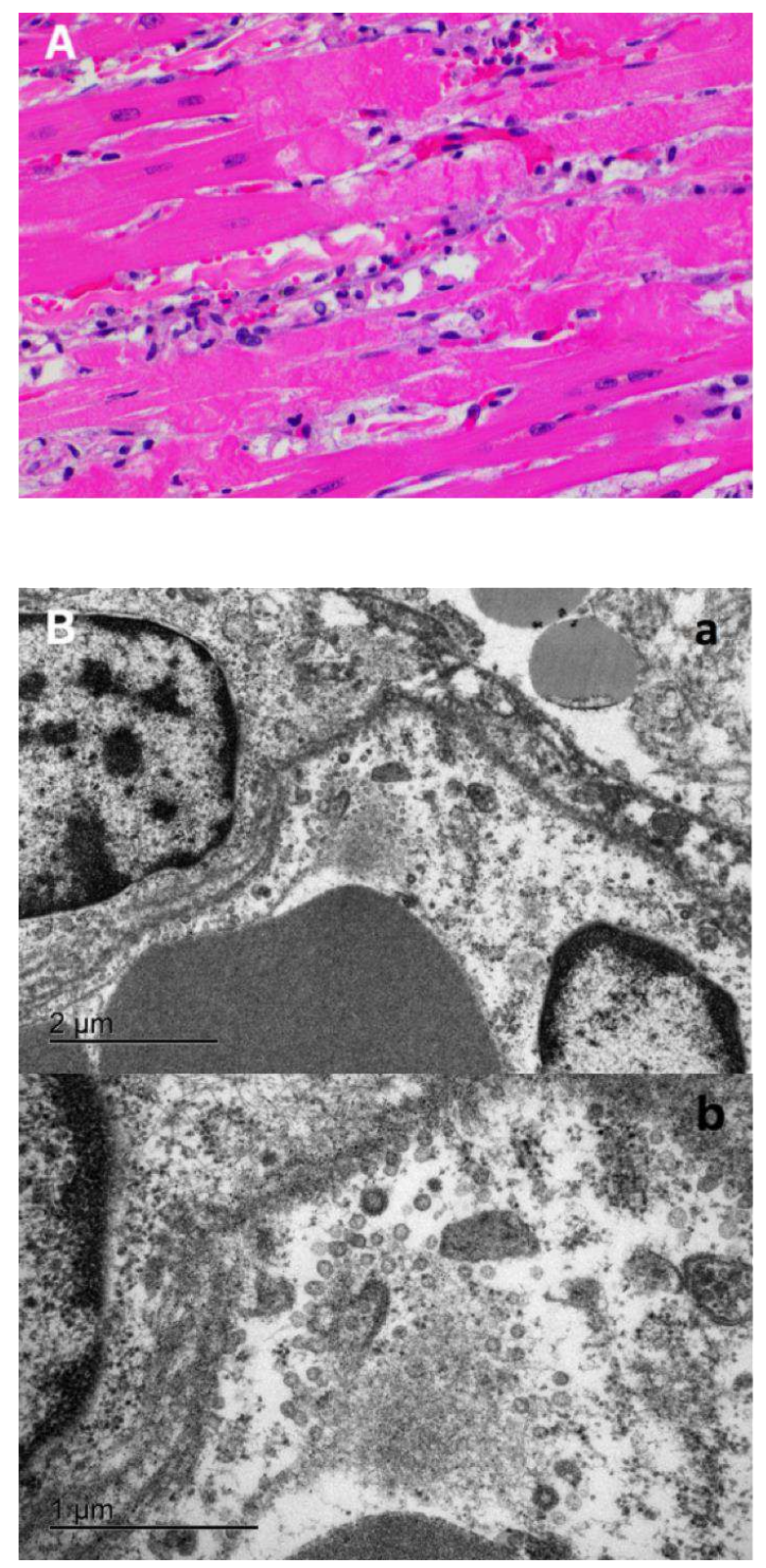

Fig. 4. Morphologic changes and viral localization in the heart of the SARS-CoV-2 infected cat. (A) Myocardial degeneration and necrosis. Cardiomyocytes with hypereosinophilic sarcoplasm with hypercontraction bands. Small numbers of neutrophils and macrophages in the myocardial interstitium. Hematoxylin and eosin. 40X magnification. (B) Electron microscopy of the ventricular myocardium. A blood vessel containing portions of two erythrocytes (lower left) and lined by two endothelial cells, each with a partial profile of the nucleus. Multiple coronavirus-like particles are within endoplasmic reticulum cisternae or are adjacent to free 10 ribosomes and fragmented cytosolic debris (autolysis) (panel a). Bar $=2 \mu \mathrm{m}$. Panel $\mathbf{b}$ - Higher magnification of panel a. Virus particles are round with an outer double membrane and a core that contains variably distinct electron dense dots representing cross sections of the nucleocapsid. Bar $=1 \mu \mathrm{m}$. 


\section{Figures}

A

B
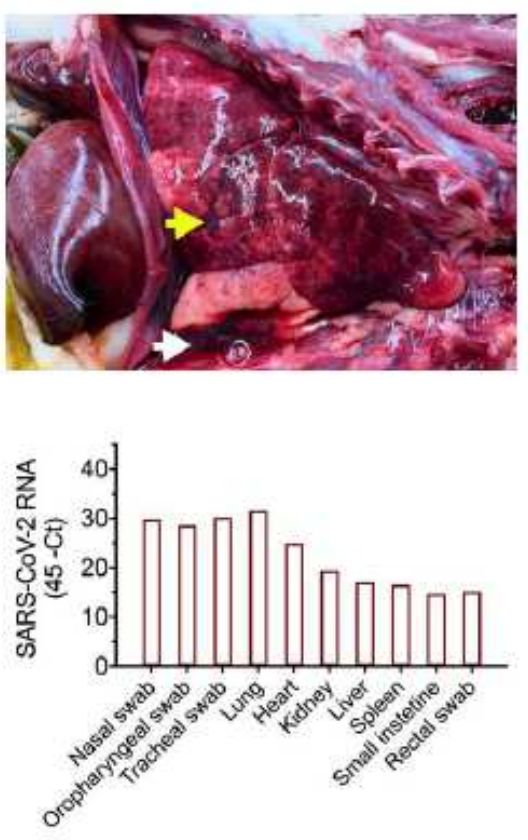

C

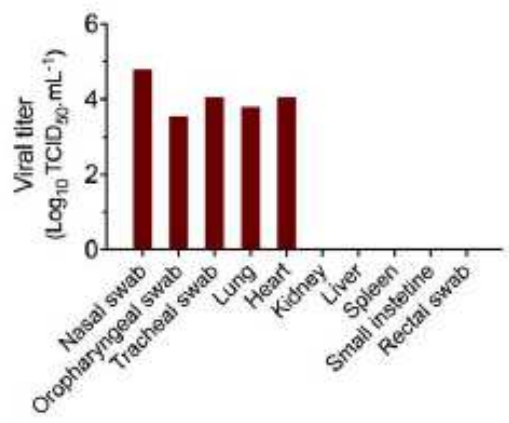

D

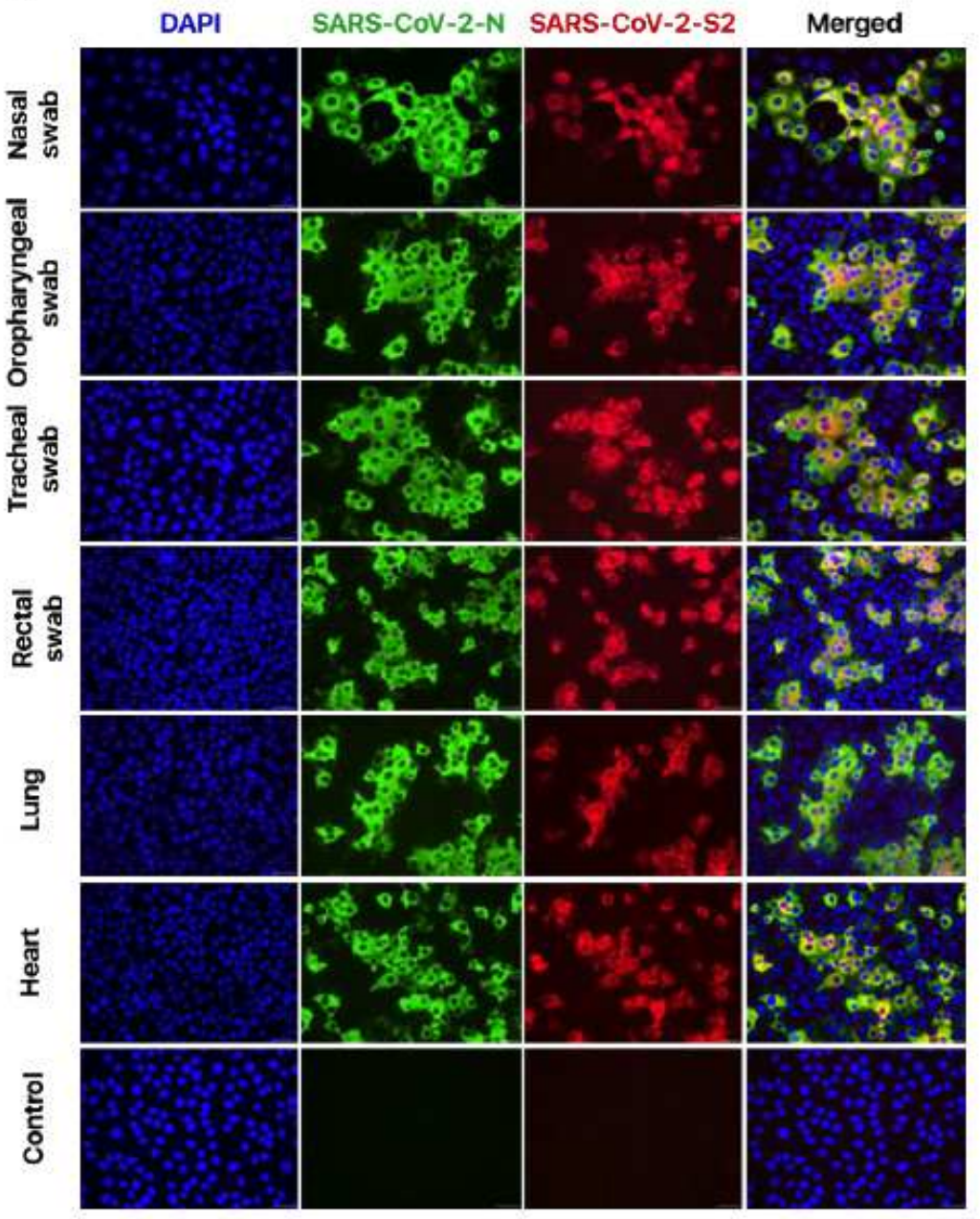

\section{Figure 1}

Gross pathological and virological findings in a domestic cat presenting progressive respiratory disease. (A) Lungs are mottled red with focal depressed areas in the parenchyma (yellow arrow). A red tinged fluid is present in the thoracic cavity (white arrow). (B) Viral loads detected in respiratory secretions, feces and in lung, heart, kidney, spleen and intestine as determined by real-time RT-PCR. (C) Viral titers in respiratory secretions, in lung and heart as determined using end-point dilutions and the Spearman and Karber's method and expressed as TCID50.mL-1. (D) Virus isolation was confirmed by immunofluorescence. For this, Vero E6/TMPRSS2 cells were inoculated with cell lysate of virus isolation assays performed in respiratory secretions, feces, lung, and heart tissue homogenate. At $24 \mathrm{~h}$ post-inoculation cells were fixed and subjected to an immunofluorescence assay using a polyclonal antibody anti-SARS-CoV-2nucleoprotein (N) (green), a mAb anti-SARS-CoV-2-Spike protein S2 subunit (red), and the nuclear counterstain performed with DAPI (blue). This confirmed isolation of SARS-CoV-2 from nasal secretions, oropharyngeal and tracheal secretions, feces and from the lungs and heart of the cat. 40X magnification. 


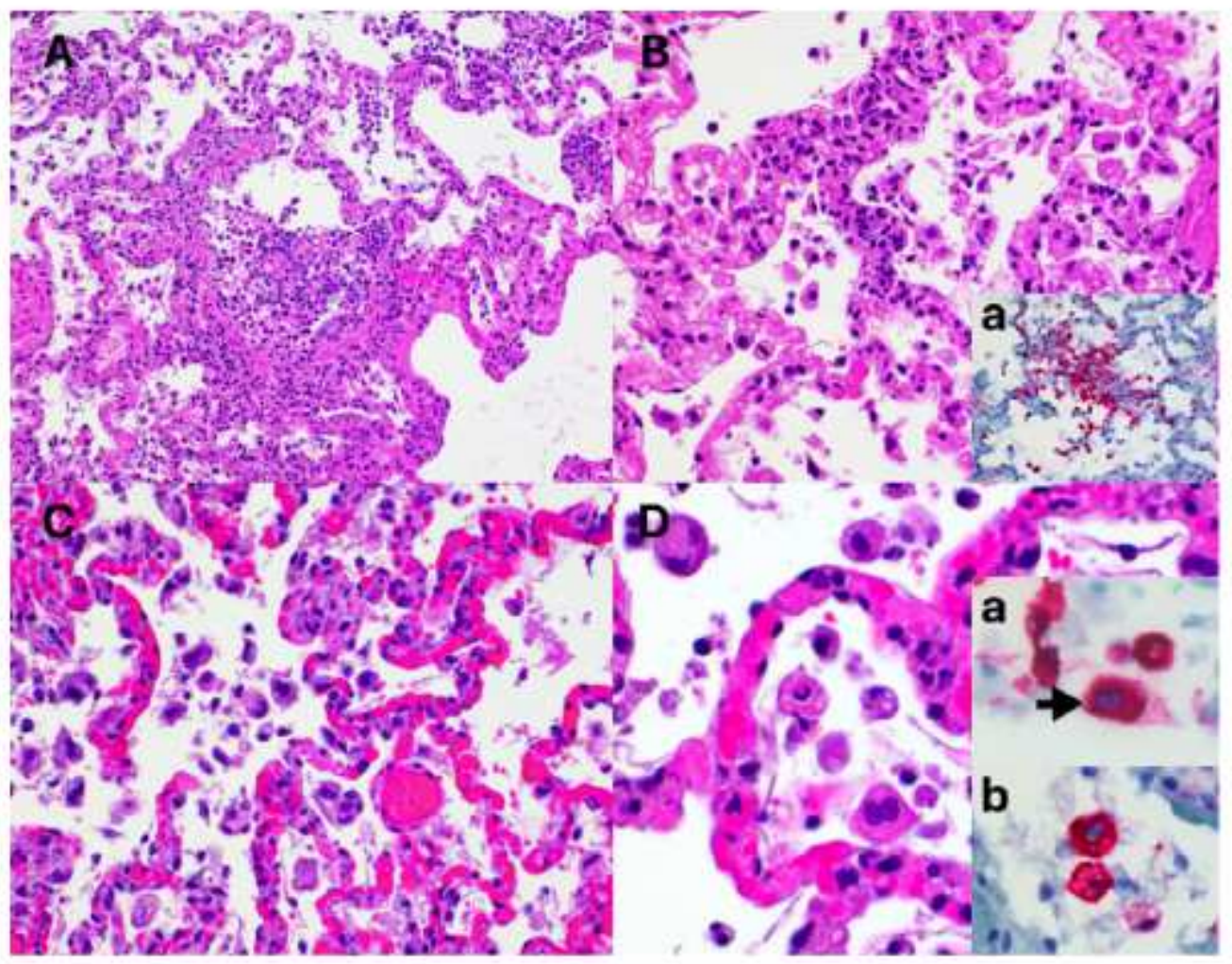

\section{Figure 2}

Histological changes in the lung of the SARS-CoV-2 infected cat. (A) Necrotizing bronchiolitis and diffuse alveolar damage (DAD), with a partially occluded bronchiole with necrotic cellular debris and inflammatory cells. Adjacent alveolar spaces contain increased cellularity, mild edema and fibrin strands, and the interstitium is expanded with numerus inflammatory cells. Hematoxylin and eosin. 20X magnification. (B) Capilaritis. Alveolar septa are infiltrated with neutrophils and macrophages. A fibrin thrombus is identified adjacent to the area of inflammation (arrow). Hematoxylin and eosin. Inset a. Iba-1 immunohistochemistry of an area of capillaritis, highlighting the presence of numerous macrophages. Mayer's hematoxylin counterstain. 40X magnification. (C) Alveolar spaces containing increased numbers of mononuclear cells and necrotic cellular debris. The alveolar septa are markedly congested with increased numbers of neutrophils and macrophages. Hematoxylin and eosin. 20X magnification. (D) Reactive atypia. Cells present in alveolar spaces, with abundant eosinophilic cytoplasm and moderately enlarged nucleus. Hematoxylin and eosin. 40X magnification. Inset a. Pancytokeratin immunohistochemistry of alveolar cells, indicative of epithelial cells. One binucleated cell is noted (syncytium, arrow). Mayer's hematoxylin counterstain. Inset b. Iba-1 immunohistochemistry of alveolar cells, indicative of macrophages. Mayer's hematoxylin counterstain. 40X magnification. 
A
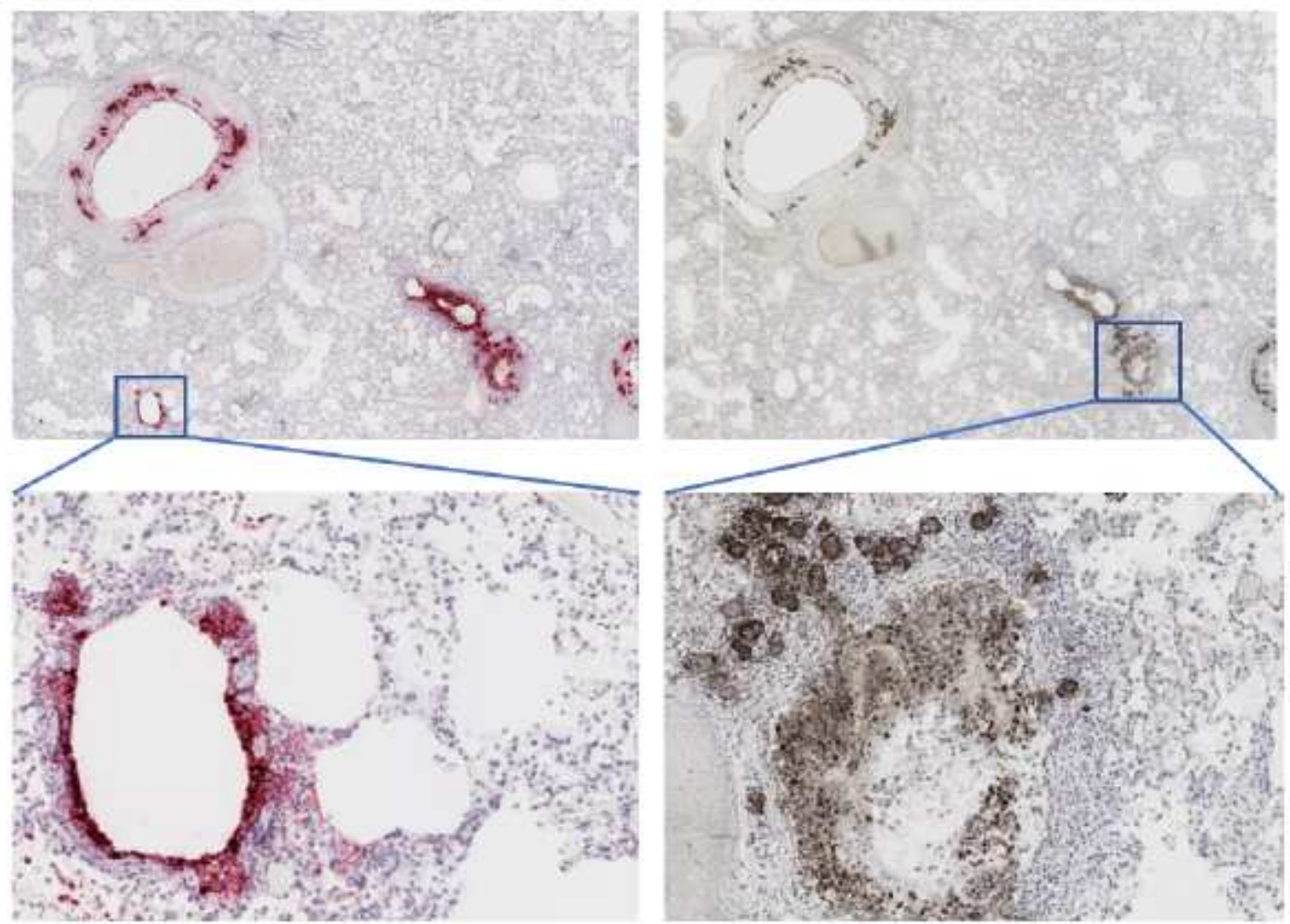

B
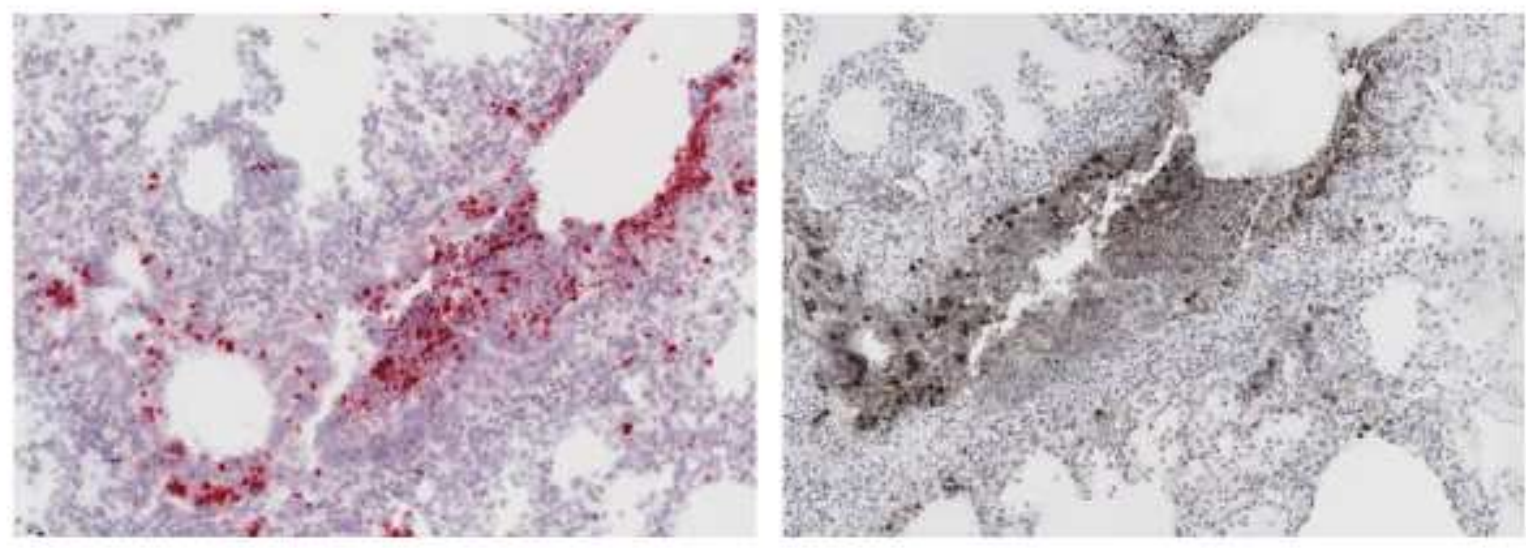

\section{Figure 3}

SARS-CoV-2 labeling in the lung of the affected cat. (A) In situ hybridization (ISH) (left panels) showing labeling (pink/reddish labeling) for SARS-CoV-2 RNA in bronchial and bronchiolar epithelial cells and bronchial glands. Immunohistochemistry (IHC) (right panels) showing staining for the SARS-CoV-2 N protein (brown stain) in bronchial and bronchiolar epithelial cells and bronchial glands. Tissue section were counter stained with hematoxylin. (B) ISH and IHC performed in the same section demonstrating colocalization of viral RNA labeling (pink/reddish) and viral protein $(\mathrm{N})$, indicating active SARS-CoV-2 replication in the lung of the cat. 

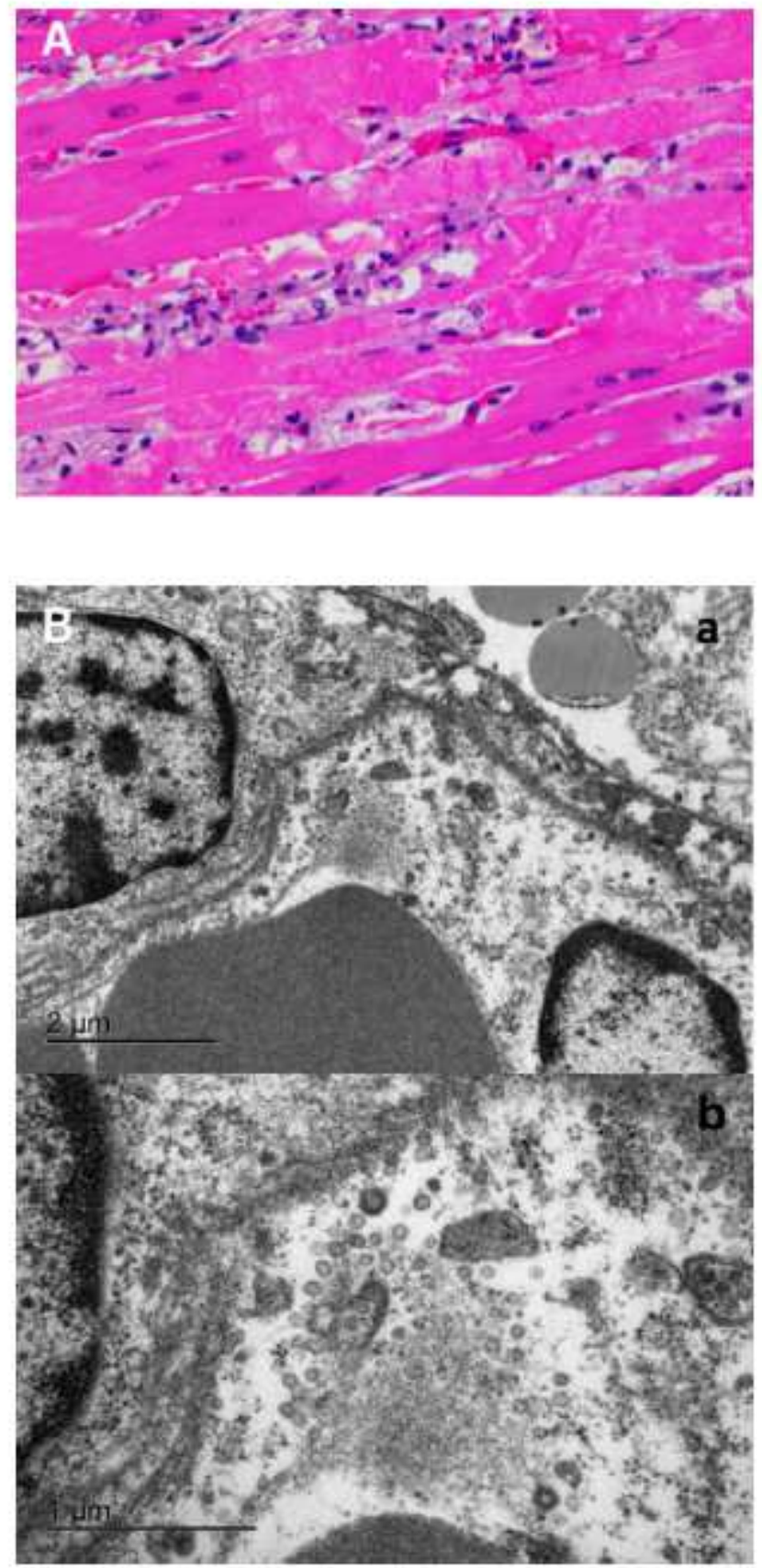

\section{Figure 4}

Morphologic changes and viral localization in the heart of the SARS-CoV-2 infected cat. (A) Myocardial degeneration and necrosis. Cardiomyocytes with hypereosinophilic sarcoplasm with hypercontraction bands. Small numbers of neutrophils and macrophages in the myocardial interstitium. Hematoxylin and eosin. 40X magnification. (B) Electron microscopy of the ventricular myocardium. A blood vessel containing portions of two erythrocytes (lower left) and lined by two endothelial cells, each with a partial profile of the nucleus. Multiple coronavirus-like particles are within endoplasmic reticulum cisternae or are adjacent to free ribosomes and fragmented cytosolic debris (autolysis) (panel a). Bar $=2 \mu \mathrm{m}$. Panel $b-$ Higher magnification of panel a. Virus particles are round with an outer double membrane and a core that 
contains variably distinct electron dense dots representing cross sections of the nucleocapsid. Bar $=1$ $\mu \mathrm{m}$.

\section{Supplementary Files}

This is a list of supplementary files associated with this preprint. Click to download.

- CarvalloMartinsSupplementaryMaterials.04.03.21.Final.pdf 